Document downloaded from:

http://hdl.handle.net/10251/80254

This paper must be cited as:

Shanthini, GM.; Sakthivel, N.; Menon, R.; Nabhiraj, PY.; Gómez-Tejedor, JA.; Meseguer Dueñas, JM.; Gómez Ribelles, JL.... (2016). Surface stiffening and enhanced photoluminescence of ion implanted cellulose - polyvinyl alcohol - silica composite. Carbohydrate Polymers. 153:619-630. doi:10.1016/j.carbpol.2016.08.016.

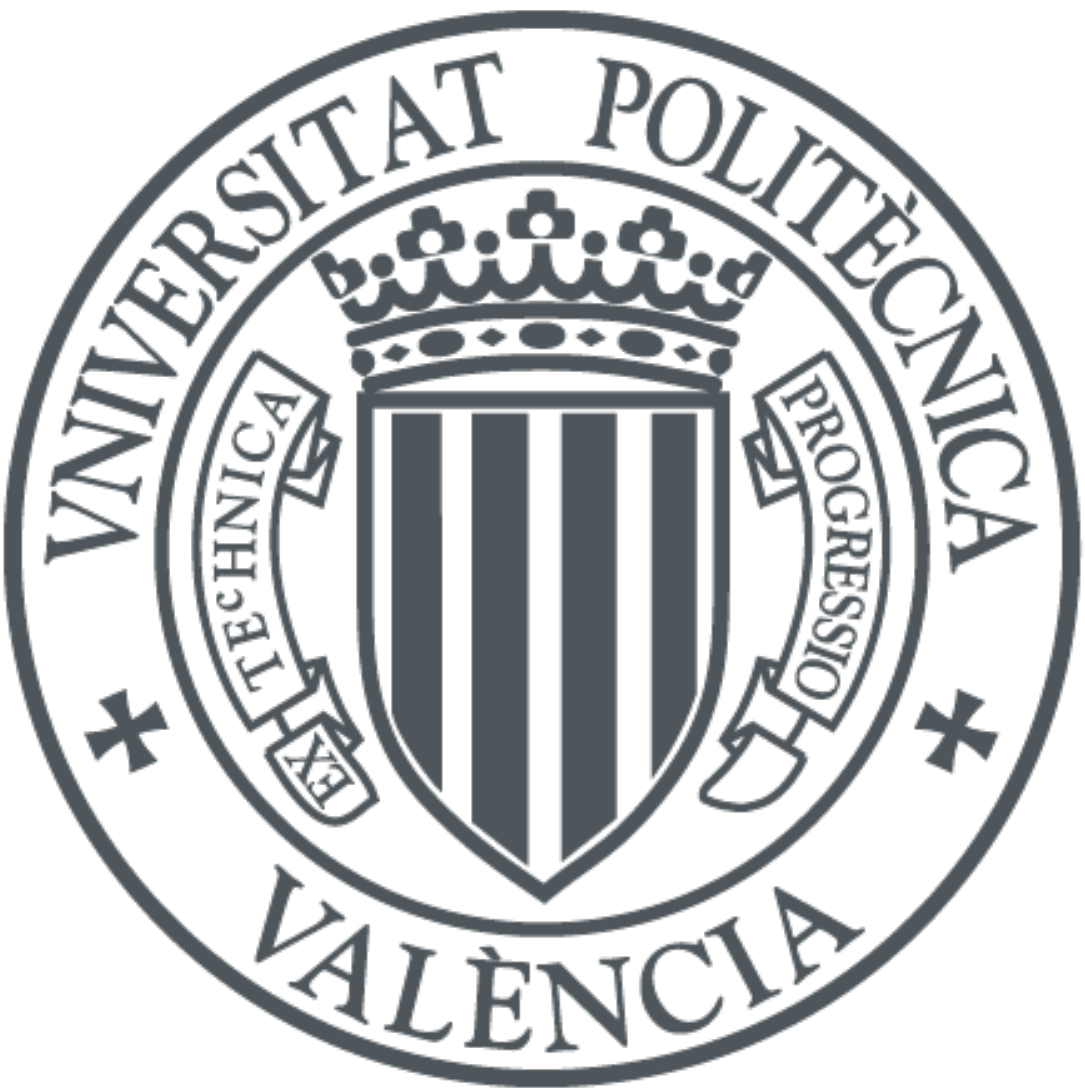

The final publication is available at

http://dx.doi.org/10.1016/j.carbpol.2016.08.016

Copyright Elsevier

Additional Information 


\title{
Surface stiffening and enhanced photoluminescence of ion implanted cellulose - polyvinyl alcohol - silica composite
}

\author{
G.M. Shanthinia, N. Sakthivela, Ranjini Menon, ${ }^{b}$, P.Y. Nabhirajb, J.A. Gómez-Tejedorc, J.M. \\ Meseguer-Dueñasc,d, J.L. Gómez Ribelles,d, J.B.M. Krishnae, S. Narayana Kalkuraa,* \\ a Crystal Growth Centre, Anna University, Chennai 600 025, India \\ b Variable Energy Cyclotron Centre (VECC), Kolkata 700064, West Bengal, India \\ c Centre for Biomaterials and Tissue Engineering, CBIT, Universitat Politècnica de València, 46022 Valencia, Spain \\ d Ciber en Bioingeniería, Biomateriales y Nanomedicina (CIBER-BBN), 46022 Valencia, Spain \\ e UGC-DAE Consortium for Scientific Research, Bidhan Nagar, Kolkata 700098, West Bengal, India \\ *Corresponding author. E-mail address: kalkura@gmail.com (S.N. Kalkura).
}

Carbohydrate Polymers 153 (2016) 619-630

http://dx.doi.org/10.1016/j.carbpol.2016.08.016

\begin{abstract}
Novel Cellulose (Cel) reinforced polyvinyl alcohol (PVA)-Silica (Si) composite which has good stability and in vitro degradation was prepared by lyophilization technique and implanted using $\mathrm{N}^{3+}$ ions of energy $24 \mathrm{keV}$ in the fluences of $1 \times$ $1015,5 \times 1015$ and $1 \times 1016$ ions $/ \mathrm{cm}^{2}$. SEM analysis revealed the formation of microstructures, and improved the surface roughness on ion implantation. In addition to these structural changes, the implantation significantly modified the luminescent, thermal and mechanical properties of the samples. The elastic modulus of the implanted samples has increased by about 50 times compared to the pristine which confirms that the stiffness of the sample surface has increased remarkably on ion implantation. The photoluminescence of the native cellulose has improved greatly due to defect site, dangling bonds and hydrogen passivation. Electric conductivity of the ion implanted samples was improved by about $25 \%$. Hence, low energy ion implantation tunes the mechanical property, surface roughness and further induces the formation of nano structures. MG63 cells seeded onto the scaffolds reveals that with the increase in implantation fluence, the cell attachment, viability and proliferation have improved greatly compared to pristine. The enhancement of cell growth of about 59\% was observed in the implanted samples compared to pristine. These properties will enable the scaffolds to be ideal for bone tissue engineering and imaging applications.
\end{abstract}

Keywords: Cellulose Silica, Ion implantation Elastic modulus Composites Photoluminescence 


\section{Introduction}

The Cellulose is the most abundant carbohydrate based poly- mer derived from wood, bacteria and agricultural plant wastes. It possesses high water retention capacity, larger surface area and excellent mechanical property. (Kumar, Negi, Choudhary, \& Bhardwaj, 2014; Missoum, Belgacem, \& Bras, 2013). Bacterial cellulose and regenerated cellulose, are extensively studied in the field of biomedical technology. Due to its ordered structure, cellulose I crystallite acquire the elastic modulus of $128 \mathrm{GPa}$. Hence, cellulose can be reinforced with other polymers to make the composites with improved mechanical property. Takagi and his coworkers reported cellulose reinforced epoxy resin composite exhibits elastic modulus of 74 MPa (Takagi, Nakagaito, \& Uchida, 2012). The high surface area and low density of cellulose help to improve the loading capacity of biomolecules such as DNA, RNA, proteins and drug molecules in order to attain high therapeutic value (Dufresne, 2013; Esmaeili et al., 2015). Bacterial cellulose and regenerated cellulose, are extensively studied in the field of Bioengineering as composites in the form of fibers, films and hydrogels. (Chen et al., 2009; Jipa et al., 2012). The cellulose as a composite not only enhances the mechanical properties of the scaffolds, but also improves the surface chemistry, due to its good surface to volume ratio. (Eicchorn et al., 2010). Cellulose based polymer composites are widely studied in tissue engineering (Raghavendra et al., 2013; Zulkifli, Hussain, Rasad, \& Yusoff, 2014), dialysis, ultrafiltration, per- meation, separation (Shibazaki, Kuca, Onabe, \& Usuda, 1993), and purification (Anirudhan, Nima, \& Divya, 2013).

Polyvinyl alcohol (PVA) is the synthetic water soluble polymer with high swelling rate. Since, PVA is highly water soluble, it has to be crosslinked. The physically crosslinked PVA acquires the viscoelastic property comparable with articular cartilage. (Stocco et al., 2014). Mesoporous silica possesses a high surface area and good adsorption capability. The incorporation of mesoporous sil- ica to cellulose will aid in loading biomolecules and drugs with improved thermal stability of the cellulose matrix.

Photoluminescence of any material can be either intrinsic or extrinsic. The intrinsic PL property is due to the defect site in the material and the extrinsic property is due to the impurities. Intrinsic PL property is very essential for biomedical applications particu- larly in biosensing and imaging. Fluorescence imaging is the key technique in drug delivery and cancer diagnostics. In the recent years luminescent imaging is of interest in tissue engineering. Biodegradable, intrinsically luminescent polymers were synthe- sized and demonstrated its application in tissue engineering and bioimaging (Du, Xue, Ma, Chen, \& Lei, 2016; Zhang et al., 2013). Biodegradable photoluminescent polylactones is used in in vivo real time tracking of degradation of polymers by measuring the luminescent signal (Xie et al., 2014).

An ideal biomaterial should generally possess properties such as three dimensional porous structure, and compatibility of blood and cells. Apart from these bulk properties, any biomaterial should pos- sess good surface properties like surface morphology, topography, wettability and surface chemistry which in turn tune the overall cell adhesion, proliferation and infiltration. Hitherto, researchers have attempted in improving the surface properties 
by creating nano and micro surface roughness, porosity, wettability and surface coating to improve compatibility. The surface modification techniques like adsorption of biomolecules, coating, etching, implantation and irra- diation are being used to improve the surface properties (Goddard \& Hotchkiss, 2007). Weishaupt et al. (2015) have modified the surface of the nanofibrillated surface with TEMPO to improve the surface negative charge which further aids the immobilization of biomolecules to the surface, in addition it assisted the covalent crosslinking with EDC and glutaraldehyde. A recent survey on sur- face modification for stent application reveals that, the materials which possess the necessary bulk properties should be modified on its surface, i.e., very thin superficial layer without any distur- bance to the bulk. They further suggest that surface modification techniques like roughening, patterning, and chemical modification should be undertaken to improve the hemocompatibility of the surface (Govindarajan \& Shandas, 2014). Sugita et al. (2009) has surface modified the Ti-Ni alloy metal plates with $120 \mathrm{keV} \mathrm{He}+$ ions to develop anithrombogenic and biocompatible stents.

The surface modification techniques generally subdivided into two categories, which includes, physicochemical and biological modification. Most of the essential modifications such as surface morphology, topography, wettability, electrical conductivity, stiff- ening and photoluminescence (PL) can be achieved by a single ideal technique, i.e., modification by passing energetic ions which in turn lead to thermodynamic effect and electron confinement resulting in formation of nano/micro structures. The nanostruc- tures such as formation of ordered pores and lamellar structures will aid the encapsulation of biomolecules and drugs. The implan- tation or irradiation of energetic ions offers the possibility of producing micro and nanostructures (Popok, 2012; Resta, Quarta, Maruccio, \& Calcagnile, 2014). These properties will enable the effective cell regeneration. Among these the very essential aspects of bone regeneration lie in engineered micro and nano meter surface roughness and good mechanical properties. Bone cells need stiffer surface to grow efficiently (Corrales, Esteves, \& Vick, 2014). Hence in the present work, attempts were made to improve the surface properties of scaffolds and its response towards cell growth was investigated. Novel composite of biocompatible materials was surface modified using low energy ions and its surface properties have been studied. The composite was synthesized by incorporat- ing the cellulose and silica in the biocompatible and bio active PVA matrix. Since, PVA is highly water soluble, cellulose fibers stabilize the scaffold by cross-linking the PVA molecules, providing a stable structure suitable for biomedical applications. In this per- spective, the effect of surface properties on the bone regeneration was investigated using MG63 osteoblast-like cells.

\section{Materials and methods}

\subsection{Materials}

Cellulose from the cotton linters was purchased from Hime- dia, Polyvinyl alcohol (PVA, Molecular weight 1,25,000 Da, 86-89\% degree of hydrolysis) was purchased from $\mathrm{CDH}$, Tetraethyl orthosil- icate (TEOS) was obtained from Alfa Aesar. P-123 was obtained from 
Sigma-Aldrich. Sodium hydroxide, Urea and Thiourea and Hydrochloric acid were purchased from Merck. All these reagents were used without any further purification.

\subsection{Preparation of Cel-PVA-Si scaffolds}

The mesoporous silica was synthesized by acid hydroly- sis method (Muthukoori, Narayanan, Chandra, Sethuraman, \& Krishnan, 2013). $2 \mathrm{~g}$ of P-123 was added to $30 \mathrm{~g}$ of distilled water and allowed to stir to obtain the homogeneous solution. The $\mathrm{pH}$ of the surfactant solution was adjusted to $\mathrm{pH}<1$ using $2 \mathrm{M} \mathrm{HCl} .4 .5 \mathrm{~g}$ of TEOS was then added to the surfactant solution and continued stirring for $24 \mathrm{~h}$ resulting in a white precipitate which was further aged in oil bath at $80{ }^{\circ} \mathrm{C}$ for $10 \mathrm{~h}$. The mixture was then cooled and washed with distilled water and subjected to calcination at $500{ }^{\circ} \mathrm{C}$ for $6 \mathrm{~h}$ to remove the surfactant. $8 \%(\mathrm{w} / \mathrm{v})$ sodium hydroxide, $8 \%(\mathrm{w} / \mathrm{v})$ urea and $6.5 \%(\mathrm{w} / \mathrm{v})$ thiourea were mixed together in 1:1:1 vol ratio and used as solvent in the preparation of $0.5 \%(\mathrm{w} / \mathrm{v})$ cellu- lose solution. $7.5 \%(\mathrm{w} / \mathrm{v})$ PVA solution was prepared using distilled water. $0.5 \%$ cellulose and $7.5 \%$ PVA solutions were mixed in 1:2 vol ratio and allowed to stir, to obtain a homogeneous solution and hereafter denoted as Cellulose PVA solution.

$1 \%(\mathrm{w} / \mathrm{v})$ of mesoporous silica was mixed with Cellulose - PVA solution. $15 \mathrm{~mL}$ of the final solution mixture was added to polypropylene petridish (Tarsons, catalogue no - 462030, inner diameter $-9.2 \mathrm{~cm}$, depth $-1.2 \mathrm{~cm}$, wall thickness $-2 \mathrm{~mm}$ ), which was used as a mold. The freezing is done by two step freezing pro- cess in order to obtain homogeneous ice formation (Kasper \& Friess, 2011), by placing the petridish containing the solution at $20{ }^{\circ} \mathrm{C}$ for $12 \mathrm{~h}$. The resultant frozen content of about $4 \mathrm{~mm}$ thick was lyophilized at $110{ }^{\circ} \mathrm{C}$ (pressure $0.002 \mathrm{mbar}$ ) for $8 \mathrm{~h}$ for complete drying of scaffolds (Doillon, Whyne, Brandwein, \& Silver, 1986). The resulting free standing Cellulose-Polyvinyl alcohol-Silica (Cel-PVA- Si) composite scaffold with about $300 \mu \mathrm{m}$ thickness was obtained and this serves as pristine.

These scaffolds were further implanted with $\mathrm{N}^{3+}$ ions of energy $24 \mathrm{keV}$ in the fluences of $1 \times 10^{15}$ ions $/ \mathrm{cm}^{2}, 5 \times 10^{15}$ ions $/ \mathrm{cm}^{2}$ and $1 \times 10^{16}$ ions $/ \mathrm{cm}^{2}$ at the Variable Energy Cyclotron Center, Kolkata. Hereafter, pristine and the samples implanted with fluences of $1 \times$ $10^{15}$ ions $/ \mathrm{cm}^{2}, 5 \times 10^{15}$ ions $/ \mathrm{cm}^{2}$ and $1 \times 10^{16}$ ions $/ \mathrm{cm}^{2}$ will be represented as pristine, $1 \mathrm{e} 15,5 \mathrm{e} 15,1 \mathrm{e} 16$ respectively. The ion beam current of $4-7 \mathrm{e} \mu \mathrm{A}$ was maintained during implantation. The samples of dimension $1 \mathrm{~cm} \times 1 \mathrm{~cm}$ were used for implantation.

\subsection{Characterization}

The pristine and the implanted samples were further char- acterized to study the surface changes of the bulk composite. Morphological changes were examined by Scanning Electron Microscopy (SEM) Carl Zeiss. The samples were gold coated and analyzed in the accelerating voltage of $15 \mathrm{kV}$. The penetration depth of implanted ions within the sample was measured in the SEM images using the ImageJ software. Functional group changes were measured by Fourier Transform Infrared Spectroscopy (FTIR) Jasco 6300 in the Attenuated Total Reflectance mode. Diamond crystal was used as the contact material in the ATR mode with an angle of incidence of the beam at $45^{\circ}$. The FTIR spectra of the samples was measured in the range of $4000-400 \mathrm{~cm}^{-1}$ and averaged from 32 scans at $1 \mathrm{~cm}^{-1}$ resolution. Absorbance correc- tion, noise elimination and background correction was applied using JASCO software. Impedance analysis was performed with Solartron SI 1260, Impedance/gain-phase analyzer. The photoluminescence measurements of the pristine and implanted samples were performed with Spectra Physics Argon ion - $488 \mathrm{~nm}$ and $514 \mathrm{~nm}$ tunable laser wave for doubling the wavelength of 488 
nm (244 nm laser) Horiba Jobin Monochromator $330 \mathrm{~nm}$ and $550 \mathrm{~nm}$ Photo Multiplier Tube detector. The glass transition temperature of the implanted samples was determined using differential scanning calorimetry, DSC, with purging nitrogen gas. DSC measurements were made in $5 \mathrm{mg}$ samples in the temperature range $100-170{ }^{\circ} \mathrm{C}$ at $20{ }^{\circ} \mathrm{C} / \mathrm{min}$. The change in elastic modulus and the topography of the Cel-PVA-Si composite on implantation of energetic ions were ana- lyzed with Atomic Force Microscope (AFM). AFM was performed in a NanoScope III from Digital Instruments (Santa Barbara, CA) operating in the tapping mode in air.

The Young's modulus, $E$ of the samples was determined by per- forming Hertz fitting model (Hertz, 1896; Johnson, 1985) from the AFM nanoindentation curves. In this model, it is assumed that the indenter tip is not deformable and thus it does not change during the measurement and that the Young's modulus for the indenter tip is much larger than the Young's modulus for the sample. The Hertz model for a sharp cone of tip angle $2 c$ yields to the following equa- tion for the load force, $F$ as a function of the indentation depth, $\mathbf{z}$ (Bulychev, Alekhin, Shorshorov, Ternovskii, \& Shnyrev, 1975; Ferencz, Sanchez, Blumich, \& Herrmann, 2012; Lin, Dimitriadis, \& Horkay, 2007),

$$
F=\frac{2 E \tan \phi}{\pi\left(1-v^{2}\right)} \delta^{2}
$$

where $E$ is the Young modulus and $v$ is the Poisson's ratio of the sample. For soft rubberlike materials, the Poisson ratio can be approximated by 0.5 (Ferencz et al., 2012). The antimony doped silicon tip MPP-13120-10 (TAP525A) distributed by Bruker is used in our experiment, which has a spring constant of $200 \mathrm{~N} / \mathrm{m}$ and it is suited for investigation of materials with a modulus between $1 \mathrm{GPa}$ and $20 \mathrm{GPa}$. This probe has a Front Angle (FA) $=15 \pm$ $2^{\circ}$, Back Angle $(\mathrm{BA})=25 \pm 2^{\circ}$ and a Side Angle $(\mathrm{SA})=17.5 \pm 2^{\circ}$ which corresponds to an equivalent angle of the conical tip of $15.2^{\circ}$

\subsection{Cell attachment, viability and proliferation}

MG63 cell line was procured from National Centre for Cell Sci- ences (NCCS), Pune, India and cultured in DMEM supplemented with 10\% FBS, l-glutamine, sodium bicarbonate and antibiotic solu- tion containing: Penicillin $(100 \mathrm{U} / \mathrm{mL})$, Streptomycin $(100 \mu \mathrm{g} / \mathrm{mL})$, and Amphotericin B $(2.5 \mu \mathrm{g} / \mathrm{mL})$. The cells were seeded in $25 \mathrm{~cm}^{2}$ tissue culture flask and cultured at $37{ }^{\circ} \mathrm{C}$ in a humidified $5 \% \mathrm{CO}_{2}$ incubator. The cells were passaged thrice prior to seeding onto scaffolds. The pristine and implanted samples of diameter $5 \mathrm{~mm}$ was used for cell culture and further analysis. The samples were sterilized with UV on both sides for about $1 \mathrm{~h}$ each side. The sam- ples were equilibrated with $200 \mu \mathrm{L}$ of DMEM medium overnight at $37{ }^{\circ} \mathrm{C}$ in a humidified $5 \% \mathrm{CO}_{2}$ incubator. The medium was com- pletely removed and $50 \mu \mathrm{L}$ of the cell suspension (10000 cells per 96 well) was carefully seeded on the scaffolds and incubated for $2 \mathrm{~h}$ at $37{ }^{\circ} \mathrm{C}$ in a humidified $5 \% \mathrm{CO}_{2}$ to facilitate the cell attach- ment on the scaffolds. After $2 \mathrm{~h}$ of incubation $150 \mu \mathrm{L}$ of complete medium was added slowly without disturbing the attached cells.

The cells were cultured for up to 3 days at $37{ }^{\circ} \mathrm{C}$ in a humidified $5 \% \mathrm{CO}_{2}$ incubator. The medium was changed on alternative days. The cells cultured similarly in the TCPS plate without sample serves as the control. After 3 days the attachment, proliferation and viability of MG63 cells were tested by direct observation of cells using Inverted phase contrast microscope, MTT (3-[4,5-dimethylthiazol- 2-yl]-2,5-diphenyl tetrazolium bromide) assay and live dead assay respectively. 
Briefly, the morphology of the cells attached on the scaffolds was observed on 3rd day using inverted phase contrast micro- scope (Olympus CKX41 with Optika Pro5 CCD camera). Also, cell viability and proliferation were monitored on 3rd day using MTT assay. $15 \mathrm{mg}$ of MTT (Sigma) was reconstituted in $3 \mathrm{~mL}$ PBS until completely dissolved. The test and control wells were treated with $30 \mu \mathrm{L}$ of MTT solution and further incubated at $37{ }^{\circ} \mathrm{C}$ in a humidified $5 \%$ $\mathrm{CO} 2$ incubator for $4 \mathrm{~h}$ in dark. The excess MTT was removed and $100 \mu \mathrm{L}$ of dimethyl sulphoxide (DMSO) was added, followed by the addition of $100 \mu \mathrm{L}$ of $0.05 \mathrm{M} \mathrm{HCl}$ in isopropyl alcohol were added to dissolve the formazan product. The cytotoxicity is measured in triplicate and the absorbance of formazan was measured at $595 \mathrm{~nm}$ using plate reader.

Live-dead assay was performed by adding DNA binding dyes acridine orange and ethidium bromide to the cell seeded scaf- folds. After the predetermined incubation period of 3 days, DMEM medium was removed and washed with cold PBS. The cells were then stained with the mixture of $100 \mu \mathrm{L}$ of acridine orange $(100 \mu \mathrm{g} / \mathrm{mL})$ and 100 $\mu \mathrm{L}$ of ethidium bromide $(100 \mu \mathrm{g} / \mathrm{mL})$ and allowed undisturbed at room temperature for $10 \mathrm{~min}$. Followed by incubation, the excess staining solutions were removed and washed thrice with 1X PBS. The stained cells were then observed in blue filter of fluorescence microscope(Olympus CKX41 with Optika Pro5 camera).

\section{Results and discussion}

\subsection{Scanning Electron Microscopy}

The periodic mesoporous configuration of mesoporous sil- ica was reported elsewhere in our previous report (Muthukoori, Narayanan, Chandra, Sethuraman, \& Krishnan, 2013). The crystal- lographic data of the synthesized mesoporous silica was analyzed and included in Supplementary information (Fig. S1). Fig.1 shows the morphology of pristine and implanted samples. The low energy ion implantation leads to significant morphological modification resulting in the formation of microstructures on the surface. SEM images revealed the fibrous morphology of the pristine samples (Fig. 1a). The control of ice nucleation is essential to engineer the porous morphology of the scaffolds. The antifreezing substances such as anti freezing proteins and salts like zirconium acetates are the important class of materials which controls the ice nucleation by the exposure of hydrophobic residues on ice nuclei (Duman, 2015; Mizrahy, Dolev, Guy, \& Braslavsky, 2013). The pore structure is mainly controlled by the ice nucleation, which is influenced by various parameters such as solution viscosity, concentration of the solute, growth velocity of ice crystals and pH. (Lu, Kessler, \& Davis, 2006). Deville et al. carried out detailed analysis of influence of func- tional groups on ice crystallization and found that the formation of various structures depends on functional groups (carboxylates, acetates and surfactants) (Deville, Viazzi, \& Guizard, 2012). The PVA is proved to inhibit the recrystallization and is a suitable polymer to preserve the food items at low temperature, which controls the ice nucleation (Budke and Koop, 2006; Pekor, Groth, \& Nettleship, 2010). In general the cellulose scaffolds possess collapsed porous structure on freeze drying and addition of PVA modifies the mor- phology of the cellulose scaffolds due to the control of nucleation (Dash, Li, \& Ragauskas, 2012). 

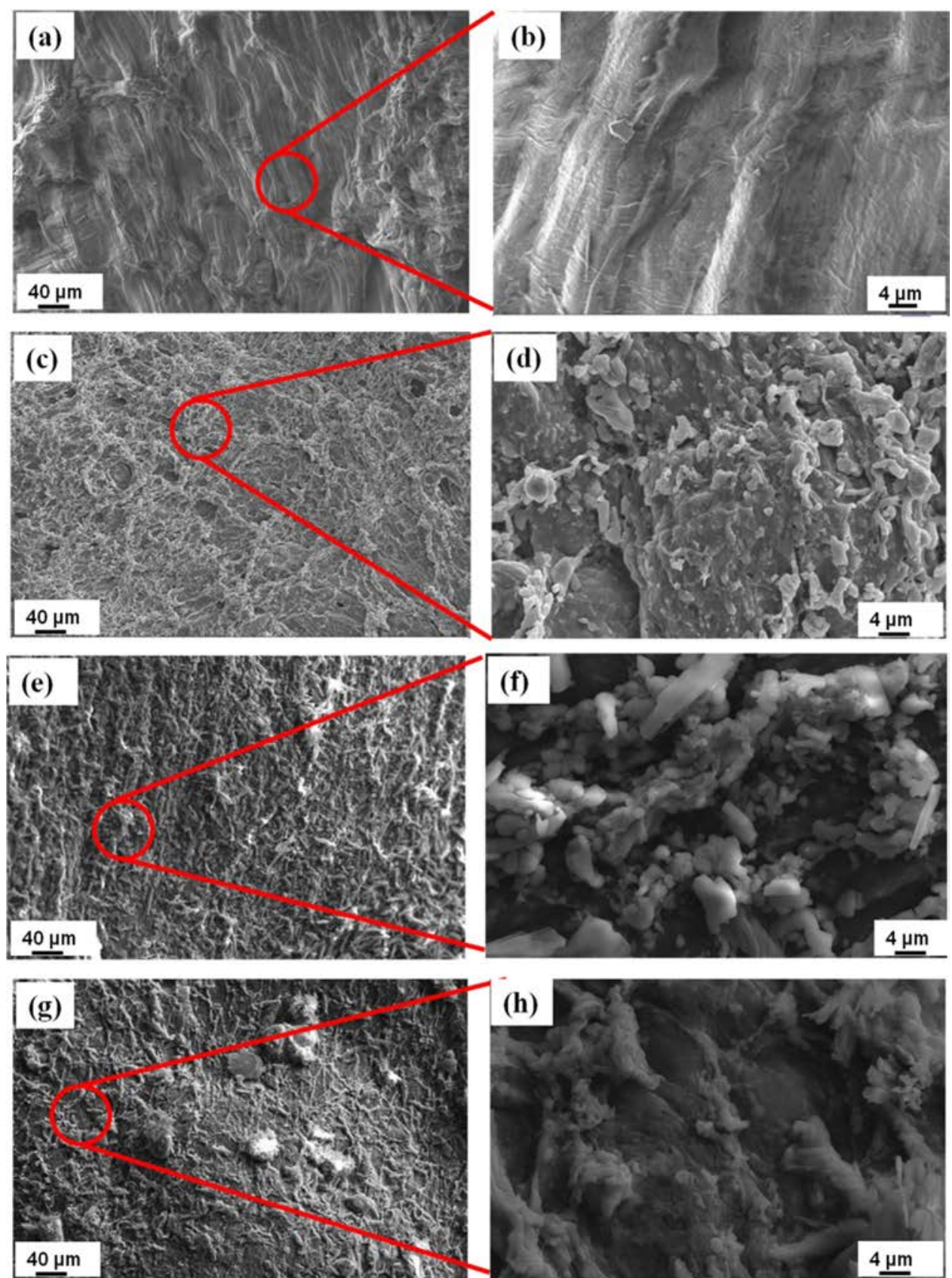

Fig. 1. SEM micrograph of a) pristine c) $1 \mathrm{e} 15 \mathrm{e}$ ) $5 \mathrm{e} 15 \mathrm{~g}$ )

1e16. b), d), f) and h) are the magnified portions of a), c), e) and g) respectively.

The lamellar morphology of the cel- lulose scaffolds in pristine clearly evidences that PVA plays an important role in the formation of lamellar/fibrous morphology. At low fluence, the platy structured layer is formed (Fig. 1c and d). Increasing the fluence, the molten platy to spherical morphol- ogy is evidenced which further transforms to a fibrous network at higher fluence. This might be due to the chain scission effect as the result of implantation. The effect of chain scission and thermal spike induced nucleation and growth were observed in 5e15, which resulted in the formation of molten platy structures (Fig. 1e and f). This result is consistent with the previous research on ion irradia- tion induced thermal spike in silica. By annealing the ion 
irradiated sample to $800{ }^{\circ} \mathrm{C}$, they have observed the smoothing of the neck of the particles formed by irradiation(Kucheyev, Wang, Hamza, \& Worsley, 2011). With further increase of the fluence, the smaller sized structures agglomerates together, forming a network (Fig. 1g and h). Thus, on implantation the sample surface gets heated up at higher fluence, enabling the grain diffusion, thereby forming larger particles. This depicts that the Ostwald ripening might have also played a major role in the formation of an implanted layer with microstructures on the surface (Resta et al., 2014).During the ion implantation, the surface of the sample gets heated up due to electron confinement. During the ion implantation, both nuclear and electronic energy loss play an equal role. As the ion fluence increases, the duration of implantation also increases, leading to prolonged local heating. The local heating leads to the motion of the particles, i.e., Brownian motion occur as a result of the ther- modynamic process(Schachoff et al., 2015). The electronic energy loss induces the nucleation by radiolysis process and these nucle- ated particles grow and precipitates in the superficial implanted layer (Meldrum, Lopez, Magruder, Boatner, \& White, 2010). Formation of micro structures might be due to the void nucleation mechanism. Void nucleation could be seen in the case of saturated vacancy solution which will be attained during ion implantation and thermal treatment process. The elongated material gets fragmented/fractured during implantation (Fig. 1c and d). When the nucleation initiates from particle fracture, the flat voids will be created initially. On continuing the implantation process, the plas- tic deformation occurs and the flat voids coalesce with each other (Fig. 1e and f). Subsequently, voids grow due to strong attraction and coalescence between themselves and get separated from the fragmented particles (Fig. 1g and h), resulting in the formation of the microstructured surface (Baset et al., 2013).

\subsection{Fourier Transform Infra Red Spectroscopy}

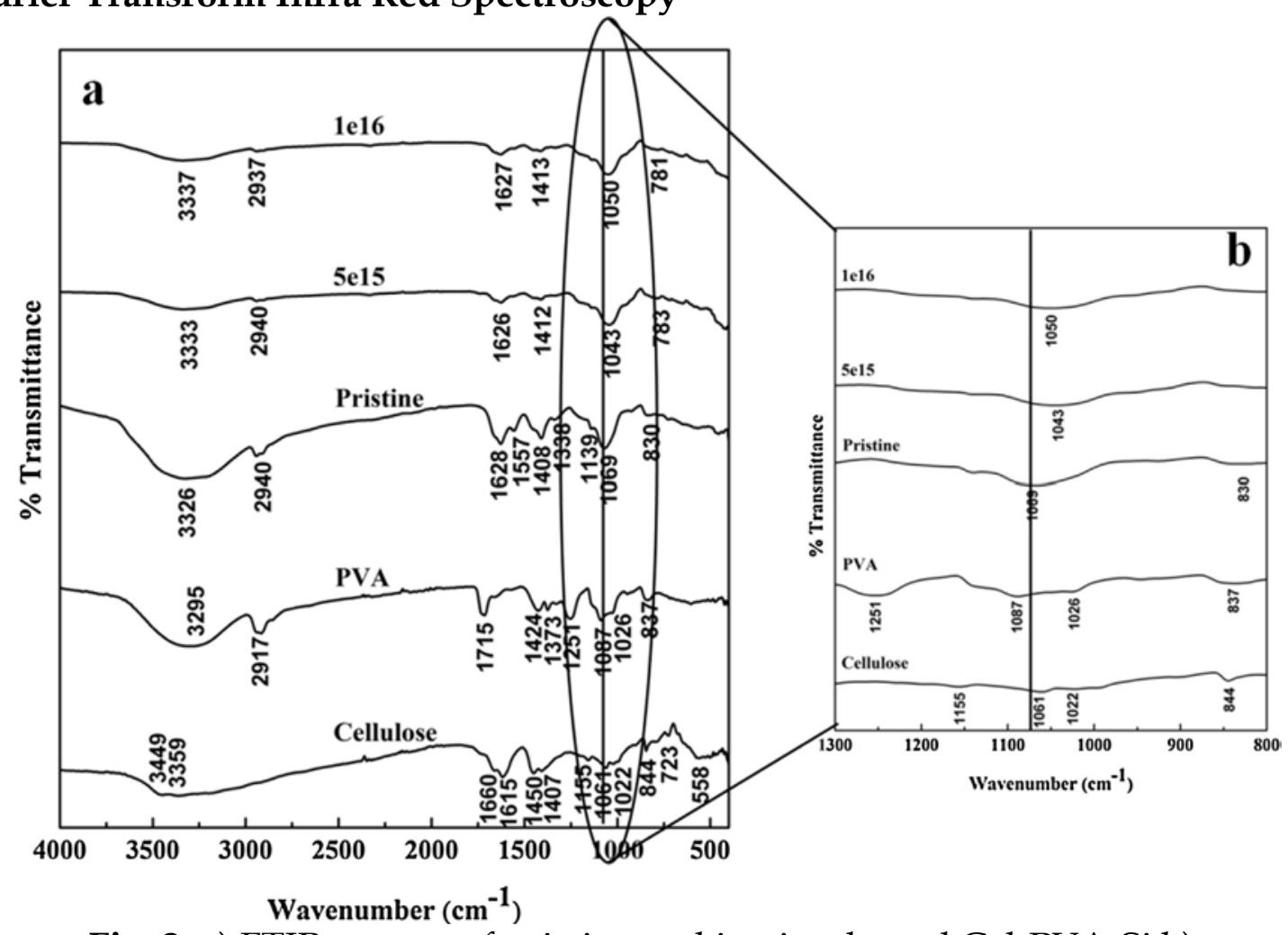

Fig. 2. a) FTIR spectra of pristine and ion implanted Cel-PVA-Si b) 
Zoomed image showing the peak shift of Si-O-Si bond

The interaction of PVA and cellulose during the fabrication of PVA cellulose composite and the effect of implantation on the poly- meric network of the composites are analyzed using FTIR (Fig. 2). The broad band observed from 3697 to $2985 \mathrm{~cm}^{-1}$ corresponds to the $\mathrm{OH}$ stretching of hydrogen bonds in the hydroxyl groups of PVA and cellulose. The decrease in the intensity of $\mathrm{OH}$ band might be due to the loss of water molecules on implantation. The peaks at 2941 and $2910 \mathrm{~cm}^{-1}$ represent C H stretching of alkyl groups in PVA. The broad peak at $1626 \mathrm{~cm}^{-1}$ is attributed to $\mathrm{OH}$ bend- ing vibration of the absorbed water molecules. C C symmetrical stretching is observed at $1505 \mathrm{~cm}^{-1}$. The intra and inter molec- ular hydrogen bonded $\mathrm{O} \mathrm{H}$ stretching of cellulose is ascribed to the bands at 3449 and $3359 \mathrm{~cm}^{-1}$ respectively. The peak observed at $1061 \mathrm{~cm}^{-1}$ is attributed to the $\mathrm{COH}$ stretching. $\mathrm{C} \mathrm{O}$ stretch- ing of $\mathrm{C}_{6} \mathrm{H}_{2} \mathrm{O}_{6}$ is observed at $1022 \mathrm{~cm}^{-1}$. The $\mathrm{CH}_{2}$ stretching of cellulose is observed at $1450 \mathrm{~cm}^{-1}$. The intermolecular hydro- gen bonded $\mathrm{O} \mathrm{H}$ stretching of PVA is observed at $3295 \mathrm{~cm}^{-1}$, the $\mathrm{CH}$ alkyl stretching vibration is observed at $2917 \mathrm{~cm}^{-1}$. The $\mathrm{CH}_{2}$ bending of PVA is observed at $1424 \mathrm{~cm}^{-1}$ and $\mathrm{CO}$ stretching of the residual acetate group is found at 1715 $\mathrm{cm}^{-1}$. The C O C stretching and C O stretching vibration of PVA is observed at 1087, $1251 \mathrm{~cm}^{-1}$ respectively. The peak found at $1373 \mathrm{~cm}^{-1}$ is due to the $\mathrm{C} \mathrm{H}$ defor- mation of PVA. The uniform distribution of silica and its interaction with the PVA/Cellulose matrix is evidenced through the broad $\mathrm{Si}$ O Si stretching observed at $1069 \mathrm{~cm}^{-1}$. The shift in the $\mathrm{Si}$ O Si stretching towards lower wavenumber indicates the binding of sil- ica with the implanted ions.

\subsection{Photoluminescence}

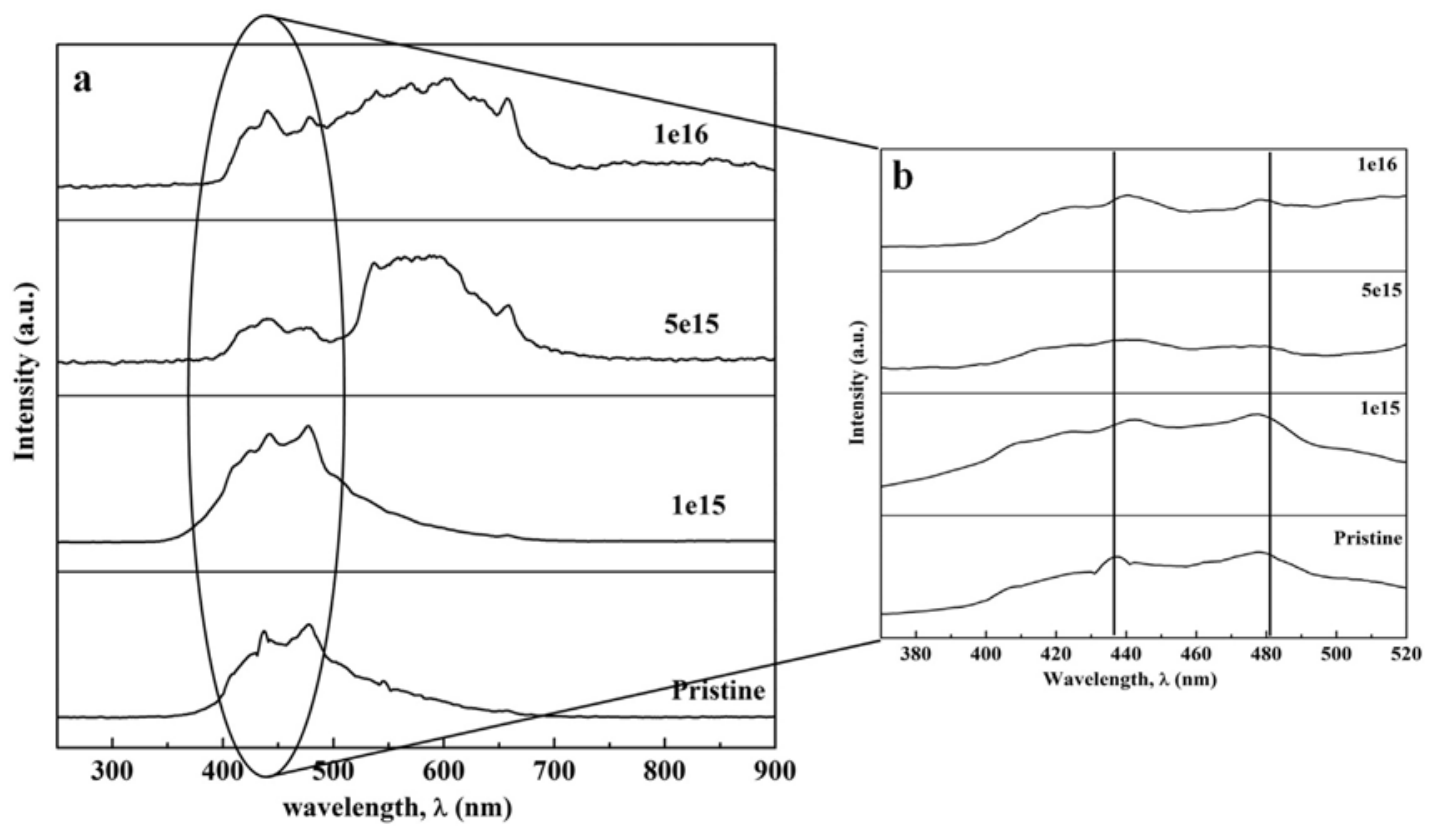

Fig. 3. a) Photoluminescence spectra of pristine and ion implanted samples b) zoomed region showing red shift.

Fig. 3 shows the effect of implantation on photoluminescence. The size of the particles and the dangling bonds in the defect site play a vital role in controlling the luminescence properties. Many reports in the recent past, has studied the influence of the defects such as 
dangling bonds and excess/deficient oxygen level on pho- toluminescence (Bansal, Pandya, Kashyap, \& Haranath, 2014). The cellulose consists of two intense PL bands at 438 $\mathrm{nm}$ and $476 \mathrm{~nm}$ in pristine (Gorelik \& Rakhmatullaev, 2004). The peak with maxima at 438 $\mathrm{nm}$ was shifted to $443 \mathrm{~nm}$ due to implantation. Whereas, the peak with maxima at $476 \mathrm{~nm}$ was shifted to $480 \mathrm{~nm}$. The reason for this slight red shift may be due to the formation of non bridg- ing oxygen species (Vaccaro, Cannas, \& Boscaino, 2008), which is explained by the peak shift from $1069 \mathrm{~cm}^{-1}$ to $1050 \mathrm{~cm}^{-1}$ in FTIR. The thermal disruption of surface hydroxyl groups, as observed by the decrease in the intensity of the broad band in the range of 3697-2985 $\mathrm{cm}^{-1}$ attributes to the formation of non bridging oxy- gen species. In addition to the red shift, an increase in intensity was observed in case of 1e15 compared to the pristine, because on ion implantation, the surface gets heated up and forms defec- tive monolayers on the surface. The surface temperature increases with the increase in fluence. At lower temperature, the increase in peak intensity was observed. As the temperature increases fur- ther, sudden quenching occurs and decreases the peak intensity. The observed results were consistent with the theories explained by Tongay et al., 2013. Moreover, when the sample is heated to a higher temperature, cellulose molecules break down and hydro gen passivation takes place, resulting in a decrease in intensity with an increase in ion fluence (Pikulev, Loginova, \& Gurtov, 2012). In addition, new peaks were observed between 540 and $657 \mathrm{~nm}$ in the implanted samples (5e15 and 1e16). This is attributed to the formation of the radiative recombination sites ( $\mathrm{Si} \mathrm{O}$ ) and non radiative sites (dangling Si bonds) as a result of ion implantation (Bregolin, Behar, Sias, \& Moreira, 2011). The reason behind the for- mation of new peak on implantation is very similar to the thermal annealing effect. These results were previously proved by compar- ing the photoluminescence of irradiation and thermal annealing (Tongay et al., 2013). Hence, the scaffolds with interesting lumi- nescent properties could be used in bone tissue engineering and the imaging applications.

\subsection{Differential Scanning Calorimetry (DSC)}

The thermal behavior of the pristine and ion implanted samples was as shown in Fig. 4. Two heating scans were performed on PVA, cellulose, pristine, 1e15, 5e15 and 1e16. Cellulose shows a peak around $140{ }^{\circ} \mathrm{C}$ in the first scan (Fig. 4a) which is not visible in the second scan (Fig. 4b), which might be ascribed to the dehydration of cellulose, at low fluence of ion implantation. On the other hand, the PVA sample shows a glass transition around $73^{\circ} \mathrm{C}$ in the first scan. Fig. $4 \mathrm{~b}$ represents the magnified portion and it shows that the glass transition occurred at low temperatures between $-50{ }^{\circ} \mathrm{C}$ and $20{ }^{\circ} \mathrm{C}$, which corresponds to the glass transition of PVA plasticized by water contained in the composites. 

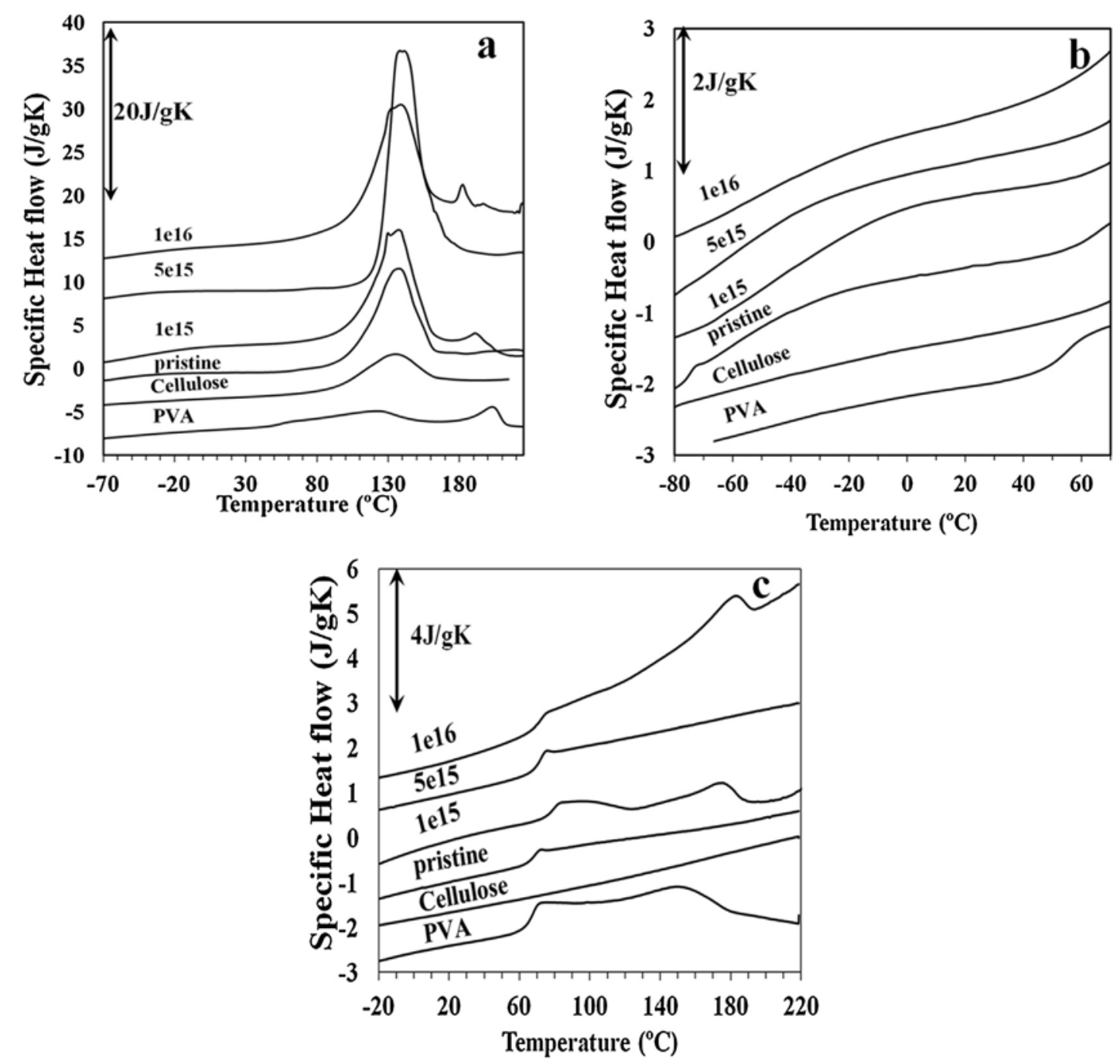

Fig. 4. a) First DSC heating scan of PVA, cellulose, and pristine and implanted composites, b) detail of the low temperature range c) Second DSC heating scan of PVA, cellulose and pristine and implanted composites

The PVA glass transition in the first scan is followed by a peak at $110{ }^{\circ} \mathrm{C}$ which is attributed to the loss of any remaining water molecule in the sample. In the composites this peak would overlap with the dehydration of cellulose. Whereas, in pure PVA, a broad exotherm appears at around $160{ }^{\circ} \mathrm{C}$ that could be due to the cold crystallization above the glass transition, when the polymer chains acquire conformational mobility. The peak around 190 ${ }^{\circ} \mathrm{C}$ is due to the melting of PVA. In the second scan, the glass transition appears at the same temperature as in the first scan. A broad crystallization exotherm appears between 80 and $140{ }^{\circ} \mathrm{C}$. The crystals formed during heating, melt immediately around $150{ }^{\circ} \mathrm{C}$. The Comparison of the second heating thermographs of pure PVA and the composites (Fig. 4c), reveals that the PVA crystallize in two of the composites, 1e16 and 1e15, presenting both cold crystallization and melting. These samples also present a clear endotherm around 190 ${ }^{\circ} \mathrm{C}$ in the first scan due to the melting of PVA (Fig. 4a). Nevertheless, in the pristine sample and in 5e15, no trace of either crystalliza- tion or melting is indicated in the second heating scan. Thus, it seems that while in some samples (pristine, 5e15) PVA is mixed with cellulose chains at a molecular level, avoiding crystallization, in other composites (1e15, 
1e16) a certain inhomogeneity in the PVA distribution allows crystallization in PVA domains. The glass transition temperature of the pure PVA, pristine and the implanted samples appear approximately at the same temper- ature. 1e15, whose glass transition is shifted around $10^{\circ} \mathrm{C}$ towards higher temperatures is an exception, a phenomenon that can be related to the ability of this sample to crystallize. Thus, DSC mea- surements show no clear influence of ion implantation on glass transition, crystallization of PVA and dehydration of cellulose. This is not unexpected since these phenomena are bulk properties of the sample and the influence of changes in the surface structure would not be significant.

\subsection{Nanoindentation studies}
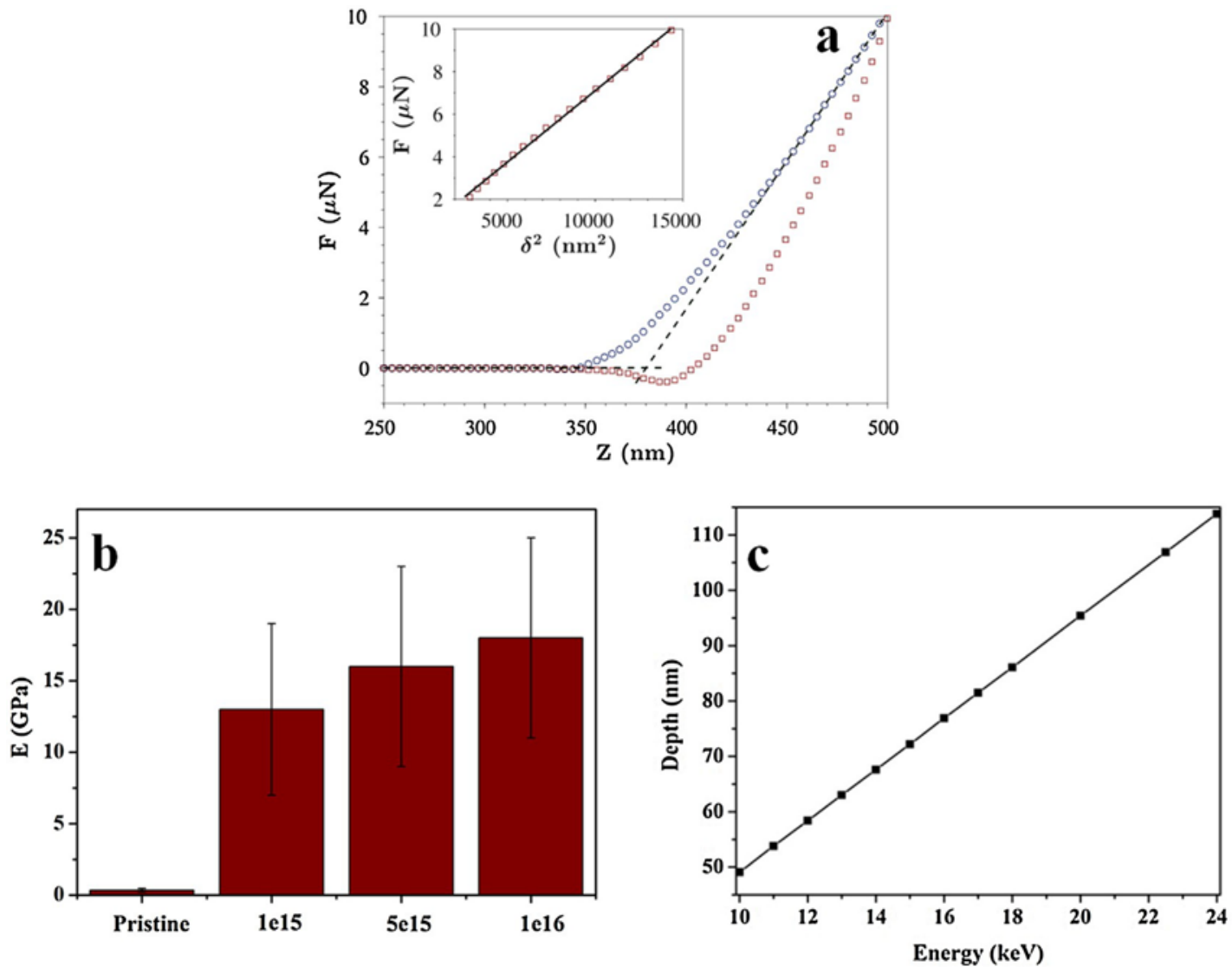

Fig. 5. a) Example of force $(F)$ versus the difference between the displacement of the sample and the cantilever deflection $(Z)$ obtained in an AFM indentation cycle for 1e16 sample. Circles correspond to the approach-displacement curve, and squares to the retract curve. Dashed

lines are used to calculate the contact point. The Young modulus is obtained from the linear fit of the force $(F)$ versus indentation depth squared $\left(8^{2}\right)$ which is represented by the black solid line in the inset figure b) Young's modulus of the samples c) Depth profile of implanted cellulose-PVA-Silica composite.

Fig 5a shows a typical approach and retract force-displacement curves obtained from AFM nanoindentation experiments. The dif- ference between the indentation force of loading and unloading is a consequence of the attraction between the tip and the mate- rial surface. 
The negative values of the force are produced close to the contact point. The contact point is calculated as the inter- section between the straight fitted line at the beginning of the indentation (nondeflected cantilever), and the straight fitted line at the maximum penetration which are represented in Fig. 5a by the two dashed lines (Colton et al., 1998; Sanchez, Mateo, Colomer, \& Ribelles, 2006; Wenger, Bozec, Horton, \& Mesquida, 2007). The Young's modulus is calculated from the fit of the Eq. (1) at the maximum depth of penetration in the initial elastic response of the unloading curve (Fischer-Cripps, 2000; Jee \& Lee, 2010), as it is shown in the inset of Fig. 5a.

The Young's modulus (E) of the samples is as shown in Fig. $5 b$

. The $E$ values stated are the average values of about 25 indents in different regions of the composites. It is evident that the elastic modulus of the ion implanted samples increased significantly com- pared to the pristine. The enhancement in Young's modulus and the surface stiffness might be due to the increased crosslinking on implantation. The stiffening effect resists the deformation when force is applied. Cross linking of the intermolecular chains of the polymer decreases the contact area of the indenter tip to the sam- ple surface, hence increases the elastic moduli. On implantation, the surface hydrogen group gets reduced due to dehydroxylation. The surface desorption and reconstruction, increases the crosslinking. In comparison with pristine, the respective increase of the elastic modulus of 1e15, 5e15 and 1e16 was about 39, 47 and 52 times. The surface stiffness of $1 \mathrm{e} 15$ has enhanced about 39 times compared to pristine. However, there is no significant change with further increase in fluences. The ion induced modification of surface stiff- ness is found through the ion path. In addition, when another ion trajectory propagates through the volume of preceding ion impact, there will be no significant change in the surface stiffness with the increase influence.

Fig. 5c shows the depth of modification on the sample surface on implanting the samples with $24 \mathrm{keV}$ of $\mathrm{N}^{3+}$ ions and was found to be $113 \mathrm{~nm}$ from the surface, which means that the stiffening effect was observed to about $113 \mathrm{~nm}$. Each and every cell exerts different force on the sample surface. Hence, the surface of the sample should possess maximum stiffness to resist the deformation or wear due to the force applied by the cells. The basic cell-material interaction, including cell adhesion, spreading and proliferation is based on mechanical signals from the cellular environment (Discher, Janmey, \& Wang, 2005).

\subsection{Atomic force microscopy}

The AFM images of pristine and $\mathrm{N}^{7+}$ ions implanted samples are given in Fig. 6. The roughness of the ion implanted samples has increased significantly compared to pristine. The roughness $(\mathrm{Rq})$ values of $57 \mathrm{~nm}, 84 \mathrm{~nm}, 142 \mathrm{~nm}$ and $102 \mathrm{~nm}$ were observed for pristine, 1e15, 5e15 and 1e16 respectively. The result eluci- dates that there was an increase in roughness until the fluence of $5 \times 10^{15} \mathrm{ions} / \mathrm{cm}^{2}$. Above which the surface roughness has decreased slightly for the high fluence $1 \times 10^{16}$ ions $/ \mathrm{cm}^{2}$. This clearly explains the fact that on ion implanting the samples with $24 \mathrm{keV} \mathrm{N}^{7+}$ ions, the samples experience electronic (negligible) and nuclear stopping (dominant). As a result, local heating occurs on the sample surface for a few picoseconds followed by sudden quenching of the heat, leading to the formation of blisters, chain scission and crosslinking. This resulted in the transformation of the smoother pristine sample to platy structure (Fig. 1c) and the forma- tion of micro structured particles as perceived in the case of 5e15 and 1e16 (Fig. 1e and g). The respective particle size was increased to about $58 \mathrm{~nm}$ and $282 \mathrm{~nm}$ for $5 \mathrm{e} 15$ and $1 \mathrm{e} 16$ with a decreased surface roughness. The change in surface roughness might also be attributed to the knock 
off of the surface atoms due to nuclear energy loss of the implanted $\mathrm{N}^{7+}$ ions.
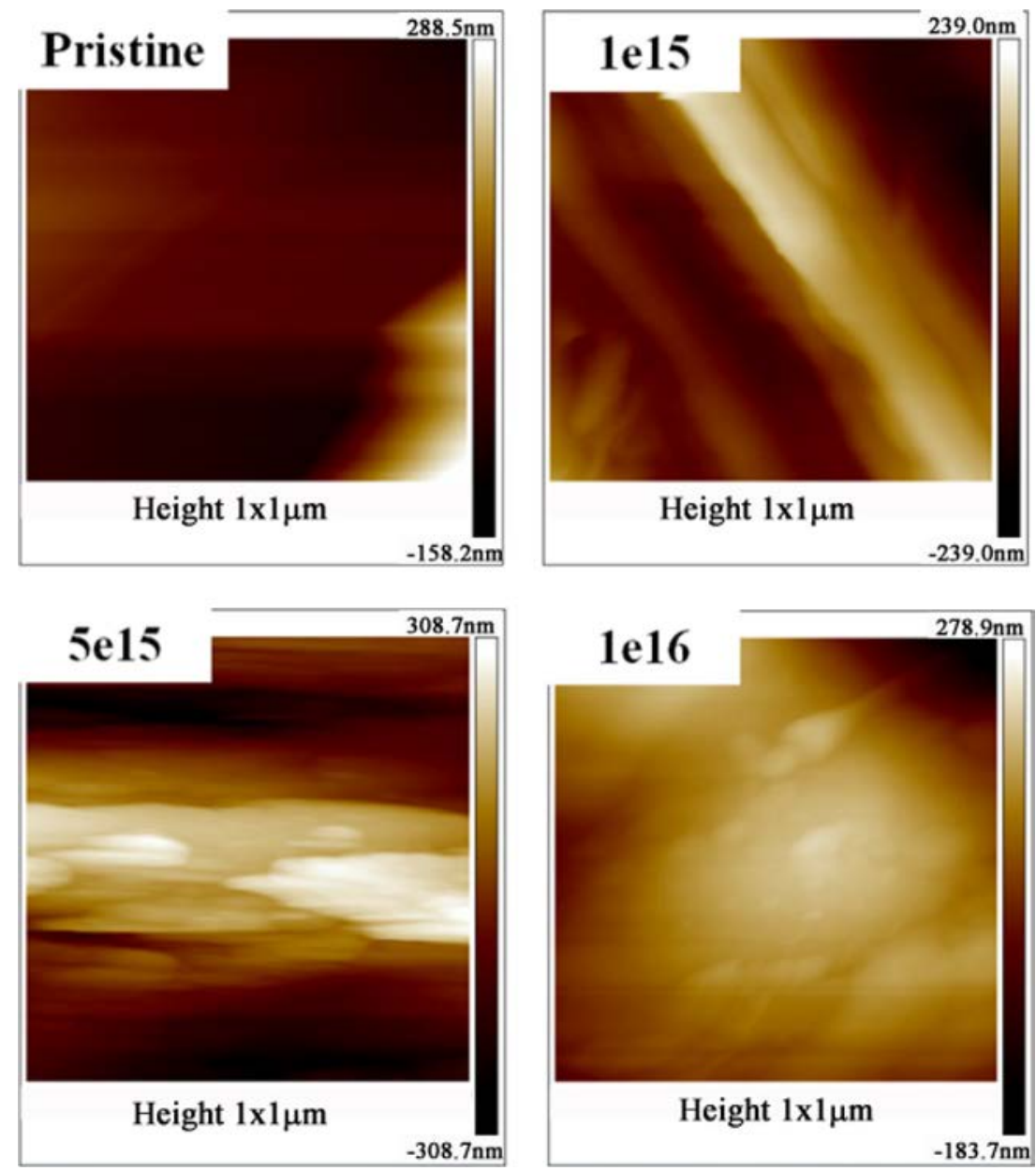

Fig. 6. AFM micrographs of pristine, 1e15, 5e15 and 1e16

\subsection{Electrical conductivity}

The electrical conductivity of the samples was carried out using impedance analysis. The dielectric behavior of the samples was explained by Nyquist plot. The Nyquist plot gives the relationship between real and imaginary parts of the impedance, which can be expressed as,

$$
Z=Z^{\prime}-\mathrm{j} Z^{\prime \prime} 1
$$

where $Z^{\prime}$ is the real part and $Z^{\prime \prime}$ is the imaginary part of the complex impedance (Shuhaimi, Teo, Woo, Majid \& Arof, 2012).

The Nyquist plots, revealed typical impedance behavior for all the samples (Fig. 7). The electrical resistance of the polymer com- posites was determined from the high frequency intercept of the semicircle with the real part of the impedance. In the graph the semicircle represents the charge transfer resistance and the subsequent tail part denotes the proton diffusion within the sample (Oakes et al., 2013). Fig. 7a illustrates that the semicircle of the pristine is very broad indicating very high resistance. Hence, the conductivity will be negligible. On ion implantation, the area of the semicircle shows the decreasing pattern, which indicates that the resistance of the samples decreases with ion fluence. The resistance values were measured to be $1.5 \times 10^{5} Q, 1.58 \times 10^{5} Q$ and $9 \times 10^{4} Q$ with respect to $1 \mathrm{e} 15,5 \mathrm{e} 15$ and 1e16. With these resistance values, the conductivity of the samples was calculated 
using the formula

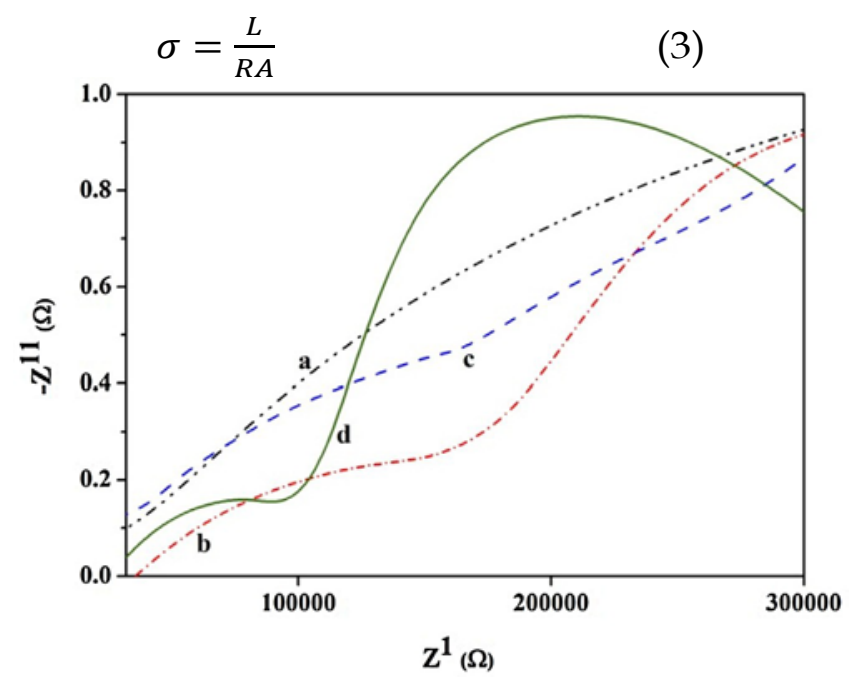

Fig. 7. Nyquist plot of a) pristine b) $1 \mathrm{e} 15$ c) $5 \mathrm{e} 15 \mathrm{~d}) 1 \mathrm{e} 16$.

where $L$ corresponds to sample thickness, $R$ is the resistance and $A$ refers to the area (Deng et al., 2013; Marins et al., 2011). The conductivity values of 1e15, $5 \mathrm{e} 15$ and $1 \mathrm{e} 16$ were found to be $1.59 \mu \mathrm{S} / \mathrm{cm}, 1.91 \mu \mathrm{S} / \mathrm{cm}$ and $2 \mu \mathrm{S} / \mathrm{cm}$, respectively. About $25 \%$ of conductivity increase was observed in 1e16 (Fig. 7b) with respect to 1e15 (Fig. 7d). Conductive scaffolds aid the cell signaling by creating electrical cues between cell and the sample, which consequently could improve the cell attachment, prolifer- ation and viability (Meng, Zhang, \& Rouabhia, 2011). Electrical signal improves the protein adsorption which could facilitate the cell attachment (Kotwal \& Schmidt, 2001; Yazdimamaghani et al., 2015).

\subsection{Cell attachment, viability and proliferation}

Quantitative and morphological representation of cell growth and proliferation was given in Fig. 8. Cell material and cell-cell interaction favors effective cell growth which could be achieved by good surface morphology, roughness, surface chemistry and sur- face stiffness (Grover et al., 2012). The toxicity is mainly induced, in case of release of any unreacted byproducts or leachants from the scaffolds. Fig. 8A shows the percentage of viable cells of pristine and implanted samples. The number of cells has increased in the implanted samples. The surface properties generally influence the initial cell attachment. The cell attachment has augmented greatly in the surface modified samples compared to pristine (Fig. 8B). As the cell attachment has increased, the increase in the per-centage viable cells was observed. Fig. 8C shows the fluorescence microscopy images of pristine and implanted samples seeded with MG63 cells by performing acridine orange and ethidium bromide double staining. Acridine orange and ethidium bromide were used in morphological detection of apoptotic and necrotic cells. Acridine orange is the cell permeable dye which will interact with nucleic acid by electrostatic attractions and will emit green fluorescence (live cells). While, ethidium bromide will be taken up only by dead cells and emits red fluorescence. The image shows that the pris- tine and the implanted samples do not induce any toxicity to cells. Fig. 8A, B and C clearly explains that, the number of cells attached and proliferation were improved with implantation fluence. In pristine, less number of cell attachment was observed and are also found to be rounded and 
viabl e (Fig. 8B(a) and C(a)). On implan- tation with low fluence of N3+ ions (1 1015 ions/cm2) the number of cells attached were increased but still perfect cell morphology was not obtained (Fig. 8B(b) and $\mathrm{C}(\mathrm{b})$ ). Further, with increasing ion fluence (5 1015 ions/cm2 and 11016 ions/cm2), the increase in cell attachment and characteristic cell morphology and shape were observed (Fig. 8B(c and $d$ ) and $C(c$ and $d)$ ). As explained earlier in the nanoindentation studies the increase in number of cell attach- ment and proliferation in the modified samples might be due to the increase in the surface stiffness (Fig. 5b) of the implanted scaf- folds. The increased surface stiffness enhances the cellular activity through the mechano-transductive pathways (Haugh, Murphy, McKiernan, Altenbuchner, \& Brien, 2011). Mechano transduction is the conversion of mechanical stimulus into biochemical or elec- trical stimulus. These signals will further stimulate the cell growth (Corrales et al., 2014). Also, the formation of microstructures (Fig. 1) and enhanced surface roughness (Fig. 6) on ion implantation might have influenced the initial cell attachment to the scaffolds(Zhao, Wang, Guo, Liu, \& He, 2015). With these fundamental results, we conclude that, the ion implantation is an ideal tool in maintaining the increased number of viable cells, which is very essential for tissue engineering applications
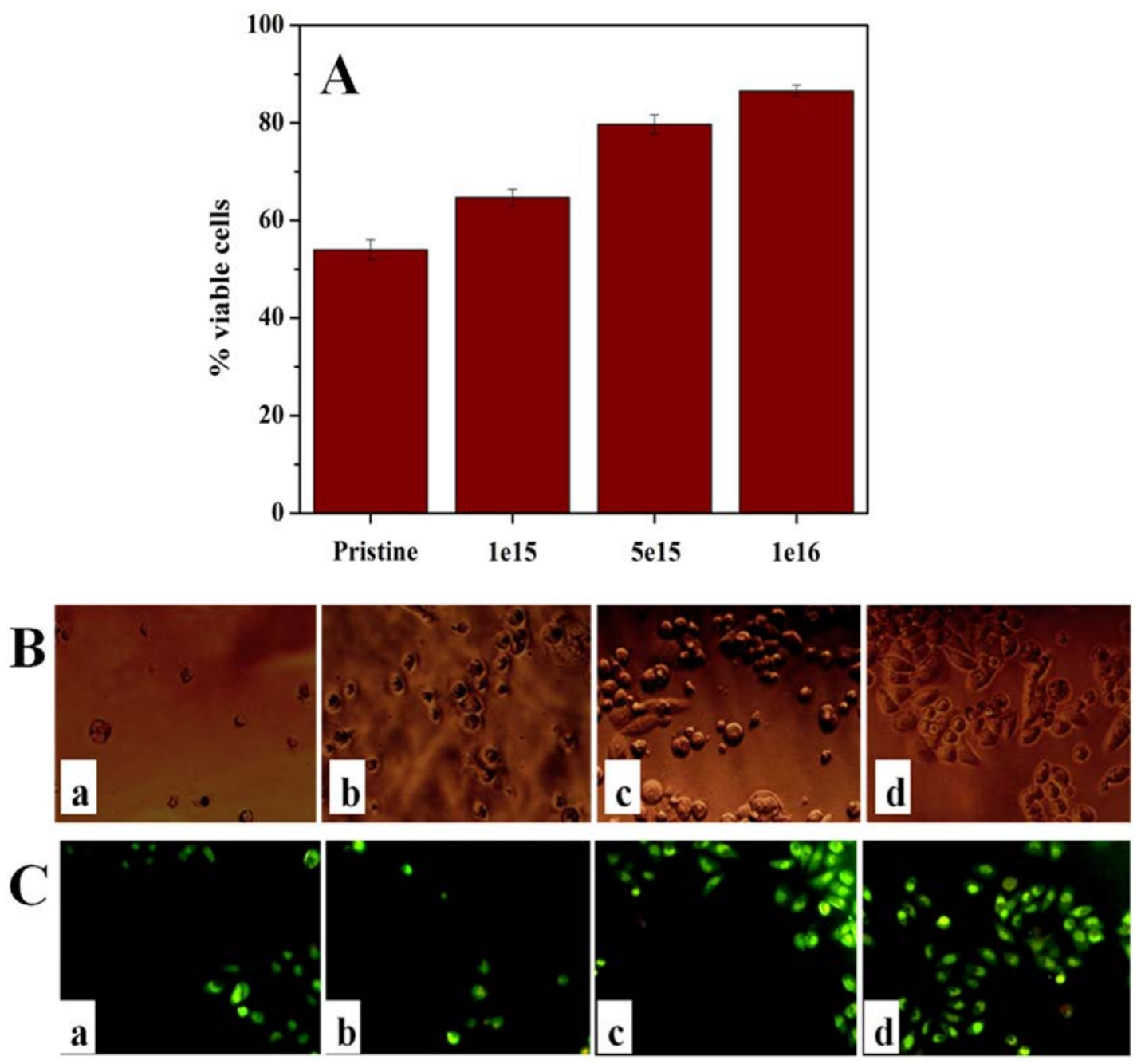

Fig. 8. A Cytotoxicity of the pristine and implanted samples. B. Phase 
contrast images of a) Pristine b) $1 \mathrm{e} 15$ c) $5 \mathrm{e} 15$ d) 1e16. C. Fluorescence microscopy images of a) Pristine b) 1 e15 c) 5 e15 d) 1e16. All the images were taken in $10 \times$ magnification

\section{Conclusions}

The implantation of $24 \mathrm{keV}$ nitrogen ions in Cel-PVA-Si compos- ite and the corresponding modifications in the physical, thermal and mechanical properties have been studied. The implantation leads to the formation of microstructures due to nucleation and Ostwald ripening in addition to an increase in surface roughness and the creation of hillocks with implantation fluence. The elas- tic modulus which is the function of surface stiffness has found to increase significantly in the implanted composites with respect to the pristine sample. FTIR analysis reveals that, the ion implanted samples undergo bond breakage. The glass transition temperature of the PVA phase has found to be independent of implantation flu- ence. 1e15 exhibited increased luminescence intensity, whereas, decrease in intensity was observed in the case of further increase in fluence. The low energy ion implantation has improved the con- ductivity of the Cel-PVA-Si composites. Thus, the results confirmed that the samples with improved surface morphology, topography, elastic modulus and photoluminescence can be obtained by low energy ion implantation. The implantation significantly improves the mechanical property which is equivalent to that of the natu- ral bone. The ion implantation transforms the lamellar structure to rough surface. The influence of the modified surface properties on bone cell regeneration was tested in vitro using MG63 osteoblast-like cells. The implantation of the samples enhances in vitro cell attachment, viability and proliferation. The stiff, conductive scaf- fold with intrinsic luminescent properties is the best candidate for bone tissue engineering. Hence, the low energy ion implantation is a novel tool to improve the mechanical property and to tune the surface properties of Cel-PVA-Si composite for tissue engineering and imaging applications.

\section{Acknowledgements}

G.M.S. acknowledges CSIR, India (Grant no: 09/468 (0474)/2013- EMR-I) and S.N.K. thanks the award of Erasmus-Mundus Svaagata for providing financial support to carry out this research. G.M.S., N.S. and S.N.K. acknowledge the support of UGC National facility for characterization facility. J.A.G.T. acknowledges the support of the Spanish Ministry of Economy and Competitiveness (MINECO) through the project DPI2015-65401-C3-2-R (including the FEDER financial support). CIBER-BBN, Spain is an initiative funded by the VI National R\&D Plan 2008-2011, Iniciativa Ingenio 2010, Consolider Program. CIBER actions are financed by the Instituto de Salud Carlos III with assistance from the European Regional Development Fund. AFM was conducted by the microscopy service of the UPV, whose advice was greatly appreciated.

\section{Appendix A. Supplementary data}

Supplementary data associated with this article can be found, in the online version, at http://dx.doi.org/10.1016/j.carbpol.2016.08.016. 


\section{References}

Anirudhan, T. S., Nima, J., \& Divya, P. L. (2013). Adsorption of chromium (VI) from aqueous solutions by glycidylmethacrylate-grafted-densified cellulose with quaternary ammonium groups. Applied Surface Science, 279, 441-449.

Bansal, S., Pandya, D. K., Kashyap, S. C., \& Haranath, D. (2014). Growth ambient dependence of defects, structural disorder and photoluminescence in SnO2 films deposited by reactive magnetron sputtering. Journal of Alloys and Compounds, 583, 186-190.

Baset, F., Popov, K., Villafranca, A., Guay, J. M., Rekabi, Z. A., Pelling, A. E., et al. (2013). Femtosecond laser induced surface swelling in poly-methyl methacrylate. Optics Express, 21, 12527-12538.

Bregolin, F. L., Behar, M., Sias, U. S., \& Moreira, E. C. (2011). Structural and photoluminescence properties of Si nanoclusters obtained by ion implantation into Si3N4 films. Journal of Luminescence, 131, 2377-2381.

Budke, C., \& Koop, T. (2006). Ice recrystallization inhibition and molecular recognition of ice faces by poly(vinyl alcohol). A European Journal of Chemical Physics and Physical Chemistry, 7, 2601-2606.

Bulychev, S. I., Alekhin, V. P., Shorshorov, M. K., Ternovskii, A. P., \& Shnyrev, G. D. (1975). Determining Young's modulus from the indenter penetration diagram. Zavodskaya Laboratoriya, 41, 1137-1140.

Chen, Y. M., Xi, T., Zheng, Y., Guo, T., Hou, J., Wan, Y., et al. (2009). In vitro cytotoxicity of bacterial cellulose scaffolds used for tissue-engineered bone. Journal of Bioactive and Compatible Polymers, 25, 137-145.

Colton, R. J., Engel, A., Frommer, J. E., Gaub, H. E., Gewirth, A. A., Guckenberger, R., et al. (1998). Procedures in scanning probe microscopies (1st ed.). United Kingdom: John Wiley and Sons.

Corrales, L. P., Esteves, M. L., \& Vick, J. E. R. (2014). Scaffold design for bone regeneration. Journal of Nanoscience and Nanotechnology, 14, 15-56.

Dash, R., Li, Y., \& Ragauskas, A. J. (2012). Cellulose nanowhisker foams by freeze casting. Carbohydrate Polymers, 88, 789-792.

Deng, L., Young, R. J., Kinloch, I. A., Abdelkader, A. M., Holmes, S. M., Haro-Del Rio, D. A. D., et al. (2013). Supercapacitance from cellulose and carbon nanotube nanocomposite fibers. ACS Applied Materials and Interfaces, 5, 9983-9990.

Deville, S., Viazzi, C., \& Guizard, C. (2012). Ice-structuring mechanism for zirconium acetate. Langmuir, 28, 14892-14898.

Discher, D. E., Janmey, P., \& Wang, Y. L. (2005). Tissue cells feel and respond to the stiffness of their substrate. Science, 310, 1139-1143.

Doillon, C. J., Whyne, C. F., Brandwein, S., \& Silver, F. H. (1986). Collagen based wound dressings: Control of the pore structure and morphology. Journal of Biomedical Materials Research, 20, 1219-1228. 
Du, Y., Xue, Y., Ma, P. X., Chen, X., \& Lei, B. (2016). Biodegradable, elastomeric, and intrinsically photoluminescent poly(silicon-citrates) with high photostability and biocompatibility for tissue regeneration and bioimaging. Advanced Healthcare Materials, 5, 382-392.

Dufresne, A. (2013). Nanocellulose: A new ageless bionanomaterial. Materials Today, 16, 220-227.

Duman, J. G. (2015). Animal ice-binding (antifreeze) proteins and glycolipids: An overview with emphasis on phisiological function. The Journal of Experimental Biology, 218, 18461855.

Eicchorn, S. J., Dufresne, A., Aranguren, M., Marcovich, N. E., Capadona, J. R., Rowan, S. J., et al. (2010). Review: Current international research into cellulose nanofibres and nanocomposites. Journal of Materials Science, 45, 1-33.

Esmaeili, C., Abdi, M. M., Mathew, A. P., Jonoobi, M., Oksman, K., \& Rezayi, M. (2015). Synergy effect of nanocrystalline cellulose for the biosensing detection of Glucose. Sensors, 15, 24681-24697.

Ferencz, R., Sanchez, J., Blumich, B., \& Herrmann, W. (2012). AFM nanoindentation to determine Young's modulus for different EPDM elastomers. Polymer Testing, 31, 425-432.

Fischer-Cripps, A. C. (2000). A review of analysis methods for sub-micron indentation testing. Vacuum, 58, 569-585.

Goddard, J. M., \& Hotchkiss, J. H. (2007). Polymer surface modification for the attachment of bioactive compounds. Progress in Polymer Science, 32, 698-725.

Gorelik, V. S., \& Rakhmatullaev, I. A. (2004). Spectoral and temporal characteristics of the photoluminescence of cotton upon laser UV excitation. Journal of Applied Spectroscopy, 71, 661-664.

Govindarajan, T., \& Shandas, R. (2014). A survey of surface modification techniques for next-generation shape memory polymer stent devices. Polymer, 6, 2309-2331.

Grover, C. N., Gwynne, J. H., Pugh, N., Hamaia, S., Farndale, R. W., Best, S. M., et al. (2012). Crosslinking and composition influence the surface properties, mechanical stiffness and cell reactivity of collagen-based films. Acta Biomaterialia, 8, 30180-33090.

Haugh, M. G., Murphy, C. M., McKiernan, R. C., Altenbuchner, C., \& Brien, F. J. O. (2011). Crosslinking and mechanical properties significantly influence cell attachment, proliferation, and migration within collagen glycosaminoglycan scaffolds. Tissue Engineering: Part A, 17, 1201-1208.

Hertz, H. (1896). On the contact of rigid elastic solids and on hardness. In In miscellaneous papers. pp. 163-183. London: MacMillan.

Jee, A. Y., \& Lee, M. (2010). Comparative analysis on the nanoindentation of polymers using atomic force microscopy. Polymer Testing, 29, 95-99.

Jipa, I. M., Dobre, L., Stroescu, M., Guzun, A. S., Jinga, S., \& Dobre, T. (2012). Preparation and characterization of bacterial cellulose-poly(vinyl alcohol) films with antimicrobial properties. Materials Letters, 66, 125-127. 
Johnson, K. L. (1985). Contact mechanics (9th ed.). Cambridge: Cambridge University Press.

Kasper, J. C., \& Friess, W. (2011). The freezing step in lyophilization: Physico-chemical fundamentals, freezing methods and consequences on process performance and quality attributes of biopharmaceuticals. European Journal of Pharmaceutics and Biopharmaceutics, 78, 248-263.

Kotwal, A., \& Schmidt, C. E. (2001). Electrical stimulation alters protein adsorption and nerve cell interactions with electrically conducting biomaterials. Biomaterials, 22, 10551064.

Kucheyev, S. O., Wang, Y. M., Hamza, A. V., \& Worsley, M. A. (2011). Light-ionirradiation-induced thermal spikes in nanoporous silica. Journal of Physics D: Applied Physics, 44, 1-5.

Kumar, A., Negi, Y. S., Choudhary, V., \& Bhardwaj, N. K. (2014). Characterization of cellulose nanocrystals produced by acid-hydrolysis from sugarcane bagasse as agro-waste. Journal of Materials Physics and Chemistry, 2, 1-8.

Lin, D. C., Dimitriadis, E. K., \& Horkay, F. (2007). Robust strategies for automated AFM force curve analysis-I. Non-adhesive indentation of soft, inhomogeneous materials. Journal of Biomechanical Engineering, 129, 430-440.

Lu, K., Kessler, C. S., \& Davis, R. M. (2006). Optimization of a nanoparticle suspension for freeze casting. Journal of American Chemical Society, 89, 2459-2465.

Marins, J. A., Soares, B. G., Dahmouche, K., Ribeiro, S. J. L., Barud, H., \& Bonemer, D. (2011). Structure and properties of conducting bacterial cellulose-polyaniline nanocomposites. Cellulose, 18, 1285-1294.

Meldrum, A., Lopez, R., Magruder, R. H., Boatner, L. A., \& White, C. W. (2010). Structure and properties of nanoparticles formed by ion implantation. In H. Bernas (Ed.), Materials Science with ion beams (pp. 255-285). Berlin, Heidelberg: Springer Berlin Heidelberg.

Meng, S., Zhang, Z., \& Rouabhia, M. (2011). Accelerated osteoblast mineralization on a conductive substrate by multiple electrical stimulation. Journal of Bone and Mineral Metabolism, 29, 535-544.

Missoum, K., Belgacem, M. N., \& Bras, J. (2013). Nanofibrillated cellulose surface modification: A review. Materials, 6, 1745-1766.

Mizrahy, O., Dolev, M. B., Guy, S., \& Braslavsky, I. (2013). Inhibition of ice growth and recrystallization by zirconium acetate and zirconium acetate hydroxide. Plos one, 8, e59540.

Muthukoori, S., Narayanan, N., Chandra, M. S. S., Sethuraman, S., \& Krishnan, U. M. (2013). Enzyme-entrapped mesoporous silica for treatment of uric acid disorders. Journal of Biomedical Nanotechnology, 9, 907-914.

Oakes, L., Westover, A., Mares, J. W., Chatterjee, S., Erwin, W. R., Bardhan, R., et al. (2013). Surface engineered porous silicon for stable, high performance electrochemical supercapacitors. Scientific Reports, 3, 3020.

Pekor, C., Groth, B., \& Nettleship, L. (2010). The effect of polyvinyl alcohol on the 
microstructure and permeability of freeze-cast alumina. Journal of American Chemical Society, 93, 115-120.

Pikulev, V., Loginova, S., \& Gortov, V. (2012). Luminescence properties of silicon-cellulose nanocomposite. Nanoscale Research Letters, 7, 426.

Popok, V. N. (2012). Ion implantation of polymers: Formation of nanoparticulate materials. Reviews on Advanced Materials Science, 30, 1-26.

Raghavendra, G. M., Jayaramudu, T., Varaprasad, K., Sadiku, R., Ray, S. S., \& Raju, K. M. (2013). Cellulose-polymer-Ag nanocomposite fibers for antibacterial fabrics/skin scaffolds. Carbohydrate Polymers, 93, 553-560.

Resta, V., Quarta, G., Maruccio, L., \& Calcagnile, L. (2014). Copper ion implantation of polycarbonate matrices: Morphological and structural properties. Nuclear Instruments and Methods in Physics Research B, 331, 187-190.

Sanchez, M. S., Mateo, J. M., Colomer, F. J. R., \& Ribelles, J. L. G. (2006). Nanoindentation and tapping mode AFM study of phase separation in poly(ethyl acrylate-co-hydroxyethyl methacrylate) copolymer networks. European Polymer Journal, 42, 1378-1383.

Schachoff, R., Selme, M., Bregulla, A., Cichos, F., Rings, D., Chakraborty, D., et al. (2015). Hot Brownian motion and photophoretic self-propulsion. Diffusion-fundamentals.org, 23, 1-19.

Shibazaki, H., Kuca, S., Onabe, F., \& Usuda, M. (1993). Bacterial cellulose membrane as separation medium. Journal of Applied Polymer Science, 50, 965-969.

Shuhaimi, N. E. A., Teo, L. P., Woo, H. J., Majid, S. R., \& Arof, A. K. (2012). Electrical double-layer capacitors with plasticized polymer electrolyte based on methyl cellulose. Polymer Bulletin, 69, 807-826.

Stocco, E., Barbon, S., Dalzoppo, D., Lora, S., Sartore, L., Folin, M., et al. (2014). Tailored PVA/ECM scaffolds for cartilage regeneration. Biomed Research International, 762189.

Sugita, Y., Suzuki, Y., Someya, K., Ogawa, A., Furuhata, H., Miyoshi, S., et al. (2009). Experimental evaluation of a new antithrombogenic stent using ion beam surface modification. Artificial Organs, 33, 456-463.

Takagi, H., Nakagaito, A. N., \& Uchida, H. (2012). Mechanical performance of bacterial cellulose nanofibre-reinforced epoxy composites. WIT Transactions on The Built Environment, 124, 379-386.

Tongay, S., Suh, J., Ataca, C., Fan, W., Luce, A., Kang, J. S., et al. (2013). Defects activated photoluminescence in two-dimensional semiconductors: Interplay between bound, charged and free excitons. Scientific Reports, 3, 2657.

Vaccaro, L., Cannas, M., \& Boscaino, R. (2008). Luminescence features of non-bridging oxygen hole centres in silica probed by site-selective excitation with tunable laser. Solid State Communications, 146, 148-151.

Weishaupt, R., Siqueira, G., Schubert, M., Tingaut, P., Weber, K. M., Zimmermann, T., et al. (2015). TEMPO-oxidized nanofibrillated cellulose as a high density carrier for bioactive molecules. Biomacromolecules, 16, 3640-3650. 
Wenger, M. P. E., Bozec, L., Horton, M. A., \& Mesquida, P. (2007). Mechanical properties of collagen fibrils. Biophysical Journal, 93, 1255-1263.

Xie, Z., Zhang, Y., Liu, L., Weng, H., Mason, R. P., Tang, L., et al. (2014). Development of intrinsically photoluminescent and photostable polylactones. Advanced Materials, 26, 4491-4496.

Yazdimamaghani, M., Razavi, M., Mozafari, M., Vashaee, D., Kotturi, H., \& Tayebi, L. (2015). Biomineralization and biocompatibility studies of bone conductive scaffolds containing poly(3,4-ethylenedioxythiophene): Poly(4-styrene sulfonate) (PEDOT:PSS). Journal of Materials Science: Materials in Medicine, 26, 1-11.

Zhang, Y., Tran, R. T., Qattan, I. S., Tsai, Y. T., Tang, L., Liu, C., et al. (2013). Fluorescence imaging enabled urethane-doped citrate-based biodegradable elastomers. Biomaterials, 34, 4048-4056.

Zhao, F., Wang, J., Guo, H., Liu, S., \& He, W. (2015). The effects of surface properties of nanostructured bone repair materials on their performances. Journal of Nanomaterials, 2015,893545 .

Zulkifli, F. H., Hussain, F. S. J., Rasad, M. S. B. A., \& Yusoff, M. M. (2014). Nanostructured materials from hydroxyethyl cellulose for skin tissue engineering. Carbohydrate Polymers, $114,238-245$. 